\title{
Role of Nonbond Interactions in the Glass Transition of Novolac-Type Phenolic Resin: A Molecular Dynamics
}

\section{Study}

Cheng Bian, ${ }^{\dagger}$ Shujuan Wang, ${ }^{, \dagger}$ Yuhong Liu, ${ }^{\ddagger}$ Kehe Su, ${ }^{\S}$ Xinli Jing ${ }^{\dagger}$

"Department of Applied Chemistry, School of Science and "Department of Chemical Engineering, School of Chemical Engineering and Technology, Xi'an Jiaotong University, No.28, Xianning West Road, Xi'an 710049, China.

${ }^{\S}$ Key Laboratory of Space Applied Physics and Chemistry of the Ministry of Education, School of Natural and Applied Sciences, Northwestern Polytechnical University, Xi'an, 710072, China.

\section{Supporting Information}

\section{Content}

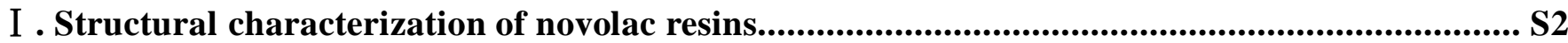

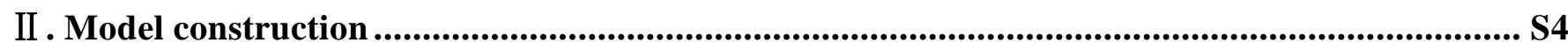

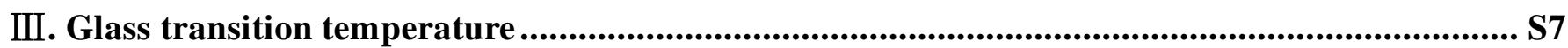

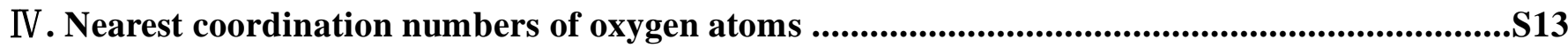

$\mathrm{V}$. Averaged reduced density gradient of frozen end phenolic rings.........................................S15

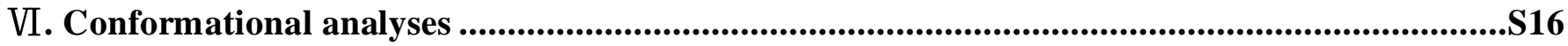




\section{I . Structural characterization of novolac resins}

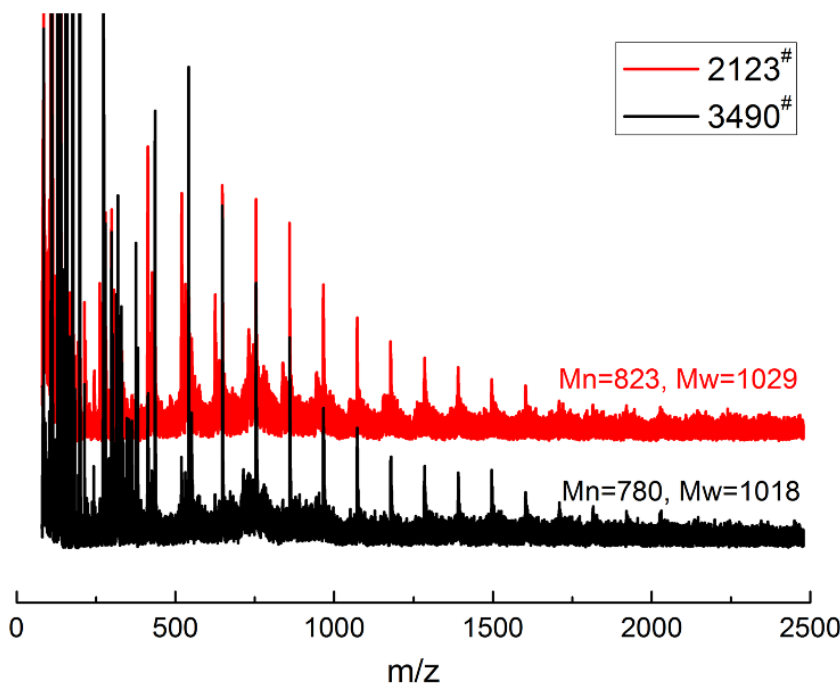

Figure S1 MALDI-TOF spectra of novolacs

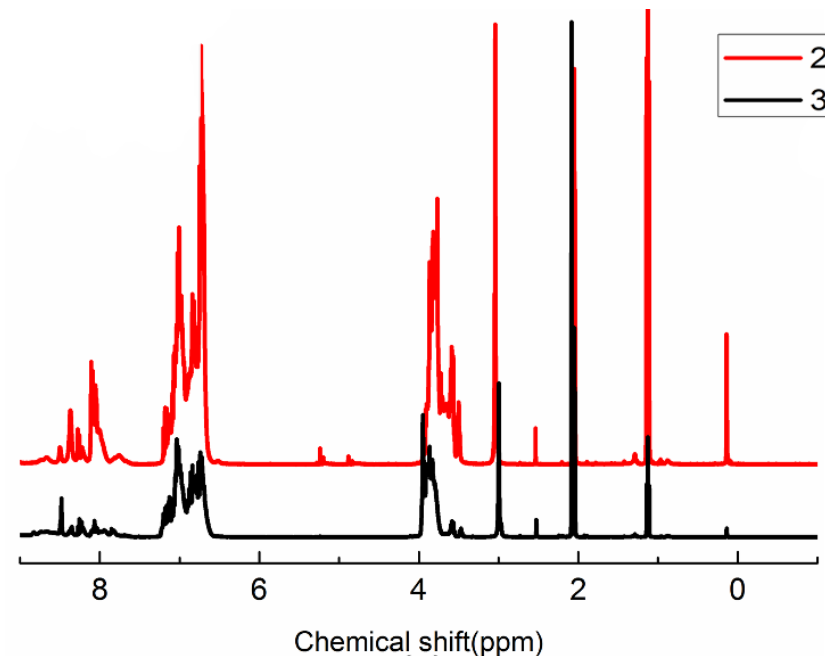

(a)

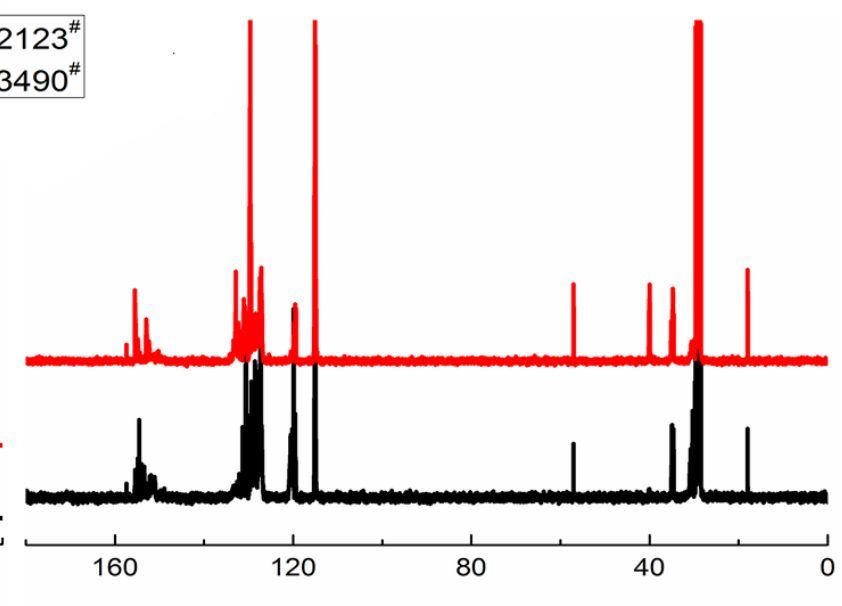

(b)

Figure S2 ${ }^{1} \mathrm{H}$ NMR (a) and ${ }^{13} \mathrm{C}$ NMR (b) spectra of novolacs 


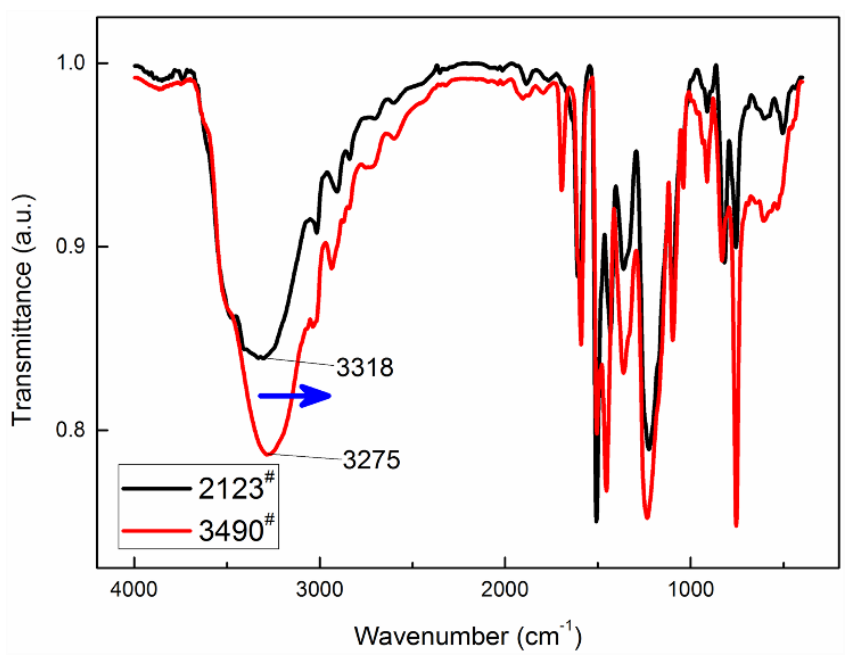

Figure S3 FTIR spectra of novolacs

Table S1 Elemental composition of novolacs

\begin{tabular}{c|cccccc|ccc}
\hline \multirow{2}{*}{ Novolacs } & \multicolumn{6}{|c|}{ Content of elements (wt\%) } & \multicolumn{4}{|c}{ Atomic ratio } \\
& $\mathbf{C}$ & $\mathbf{H}$ & $\mathbf{O}$ & $\mathbf{N}$ & S & sum & C & H & O \\
\hline $2123^{\#}$ & 76.01 & 5.85 & 17.37 & 0.23 & 0.11 & 99.57 & 6 & 5.48 & 1.03 \\
$3490^{\#}$ & 76.43 & 5.87 & 16.58 & 0.20 & 0.09 & 99.16 & 6 & 5.44 & 0.98 \\
\hline
\end{tabular}

Table S2 Properties of novolacs

\begin{tabular}{c|c|c|c}
\hline Novolacs & Density $\left(\mathrm{g} \cdot \mathrm{cm}^{-3}, 298 \mathrm{~K}\right)$ & $\mathrm{T}_{\mathrm{g}}(\mathrm{K})$ & Softening point $(\mathrm{K})$ \\
\hline $3490^{\#}$ & 1.210 & 324.1 & 378.15 \\
$2123^{\#}$ & 1.196 & 316.4 & 373.15 \\
\hline
\end{tabular}




\section{II . Model construction}

Table S3 Composition of novolac models

\begin{tabular}{|c|c|c|c|c|c|c|c|}
\hline \multirow[b]{2}{*}{ Model } & \multicolumn{2}{|c|}{ Single chain } & \multicolumn{5}{|c|}{ Bulk model } \\
\hline & Formula & $\begin{array}{l}\text { Molecular } \\
\text { weight }\end{array}$ & Chains & $\begin{array}{l}\text { Phenolic } \\
\text { rings }\end{array}$ & Atoms & $\begin{array}{l}\text { End } \\
\text { phenolic } \\
\text { rings }\end{array}$ & $\begin{array}{l}\text { Ratio of } \\
\text { end/total } \\
\text { phenolic } \\
\text { ring }\end{array}$ \\
\hline $\mathrm{PhOH}$ & $\mathrm{C}_{6} \mathrm{H}_{6} \mathrm{O}$ & 94 & 960 & 960 & 12480 & 480 & 1.00 \\
\hline Boo-2(Bop-2) ${ }^{*}$ & $\mathrm{C}_{13} \mathrm{H}_{12} \mathrm{O}_{2}$ & 200 & 480 & 960 & 12960 & 480 & 1.00 \\
\hline Boo-3(Bop-3) & $\mathrm{C}_{20} \mathrm{H}_{18} \mathrm{O}_{3}$ & 306 & 300 & 900 & 12300 & 600 & 0.67 \\
\hline Boo-4(Bop-4) & $\mathrm{C}_{27} \mathrm{H}_{24} \mathrm{O}_{4}$ & 412 & 220 & 880 & 12100 & 440 & 0.50 \\
\hline Boo-6(Bop-6) & $\mathrm{C}_{41} \mathrm{H}_{36} \mathrm{O}_{6}$ & 624 & 148 & 888 & 12284 & 296 & 0.33 \\
\hline Boo-8(Bop-8) & $\mathrm{C}_{55} \mathrm{H}_{48} \mathrm{O}_{8}$ & 836 & 120 & 960 & 13320 & 240 & 0.25 \\
\hline Boo-12(Bop-12) & $\mathrm{C}_{83} \mathrm{H}_{72} \mathrm{O}_{12}$ & 1260 & 74 & 888 & 12358 & 148 & 0.17 \\
\hline Boo-16(Bop-16) & $\mathrm{C}_{111} \mathrm{H}_{96} \mathrm{O}_{16}$ & 1684 & 56 & 896 & 12488 & 112 & 0.13 \\
\hline Boo-20(Bop-20) & $\mathrm{C}_{139} \mathrm{H}_{120} \mathrm{O}_{20}$ & 2108 & 44 & 880 & 12276 & 88 & 0.10 \\
\hline \multicolumn{3}{|c|}{ Boo-mix } & 129 & 889 & 12453 & 259 & 0.29 \\
\hline \multicolumn{3}{|c|}{ Bop-mix } & 121 & 882 & 12348 & 243 & 0.28 \\
\hline
\end{tabular}

*Boo- $\mathrm{x}$ and Bop- $\mathrm{x}$ share the same composition when the $\mathrm{DP}(\mathrm{x})$ is same. 

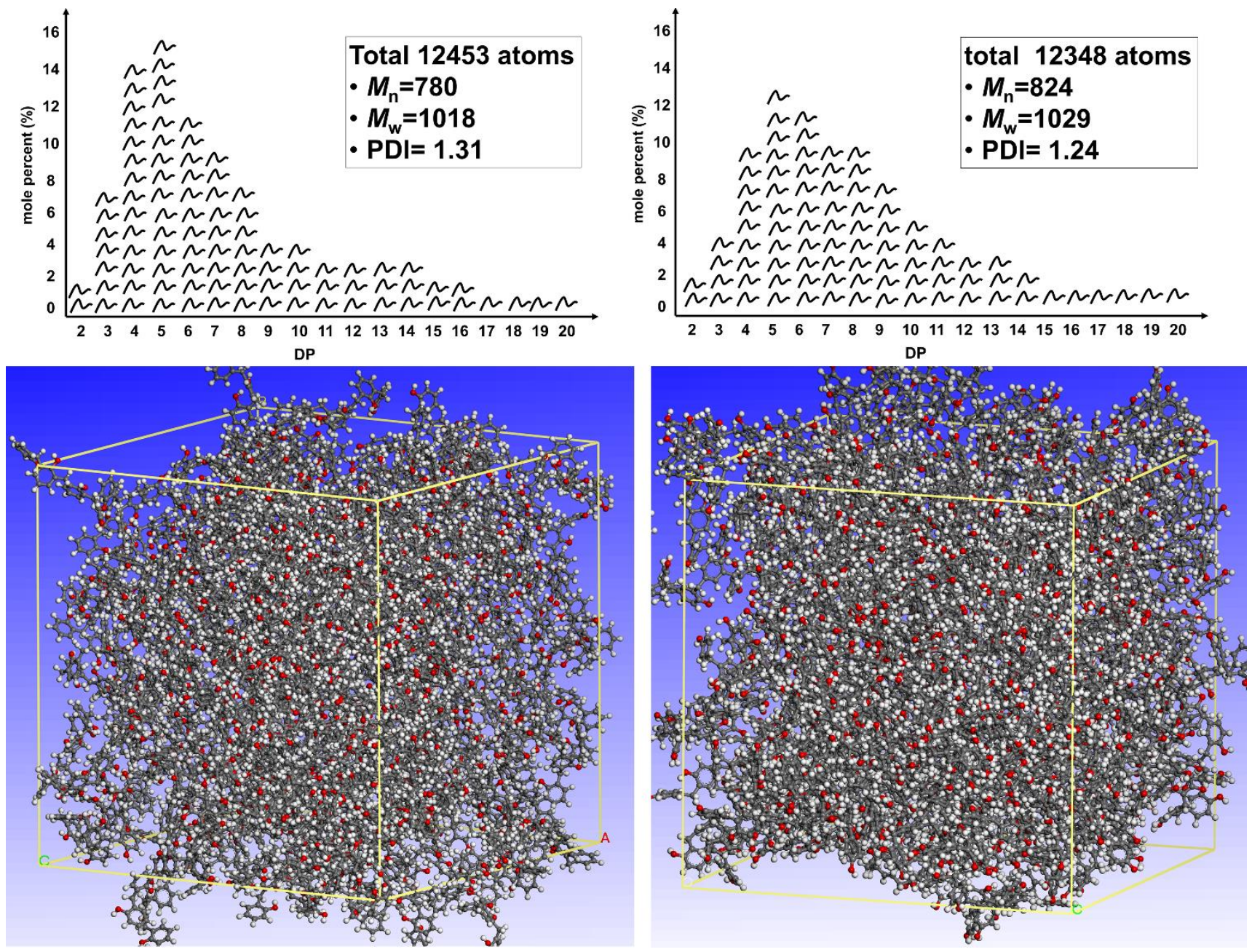

Figure S4 Molecular weight distributions and snapshots of Boo-mix and Bop-mix

Table S4 Equilibrated density of novolac models (300K)

\begin{tabular}{cc|cc}
\hline Model & $\rho / \mathrm{g} \cdot \mathrm{cm}^{-3}$ & Model & $\rho / \mathrm{g} \cdot \mathrm{cm}^{-3}$ \\
\hline PhOH & 1.069 & & \\
Boo-2 & 1.176 & Bop-2 & 1.186 \\
Boo-3 & 1.189 & Bop-3 & 1.190 \\
Boo-4 & 1.195 & Bop-4 & 1.218 \\
Boo-6 & 1.207 & Bop-6 & 1.210 \\
Boo-8 & 1.209 & Bop-8 & 1.213 \\
Boo-12 & 1.205 & Bop-12 & 1.208 \\
Boo-16 & 1.216 & Bop-16 & 1.202 \\
Boo-20 & 1.194 & Bop-20 & 1.201 \\
Boo-mix & 1.196 & Bop-mix & 1.215 \\
\hline
\end{tabular}

* Only the density of novolac models with DP $\geq 4$ were compared with the density of real novolac resins. 


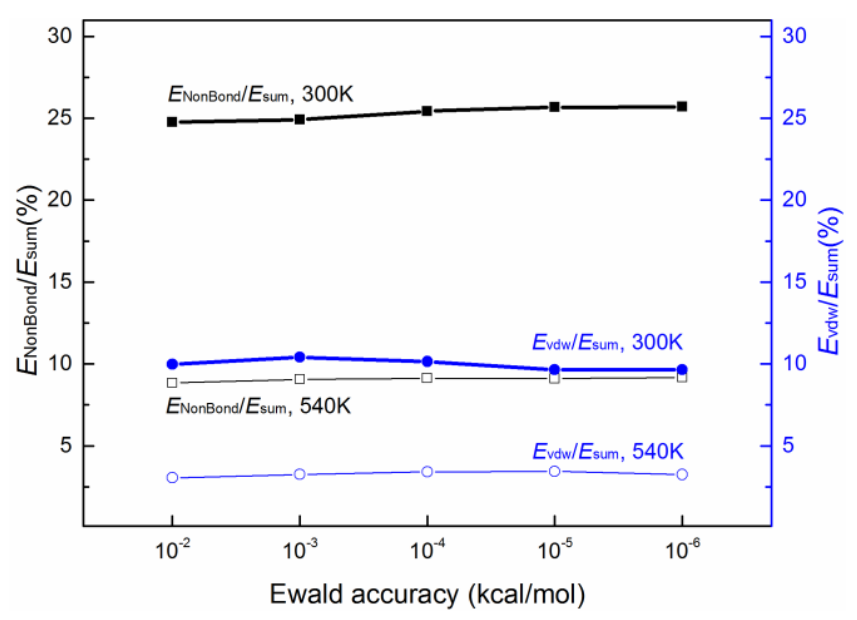

Figure S5 The proportion of nonbond interaction energy (black dots) and van der Waals energy (blue dots) in the total energy in Boo-8, calculated at different Ewald accuracy levels (the horizontal axis). It can be seen that the plots converged around the accuracy of $10^{-5} \mathrm{kcal} / \mathrm{mol}$. 


\section{Glass transition temperature}
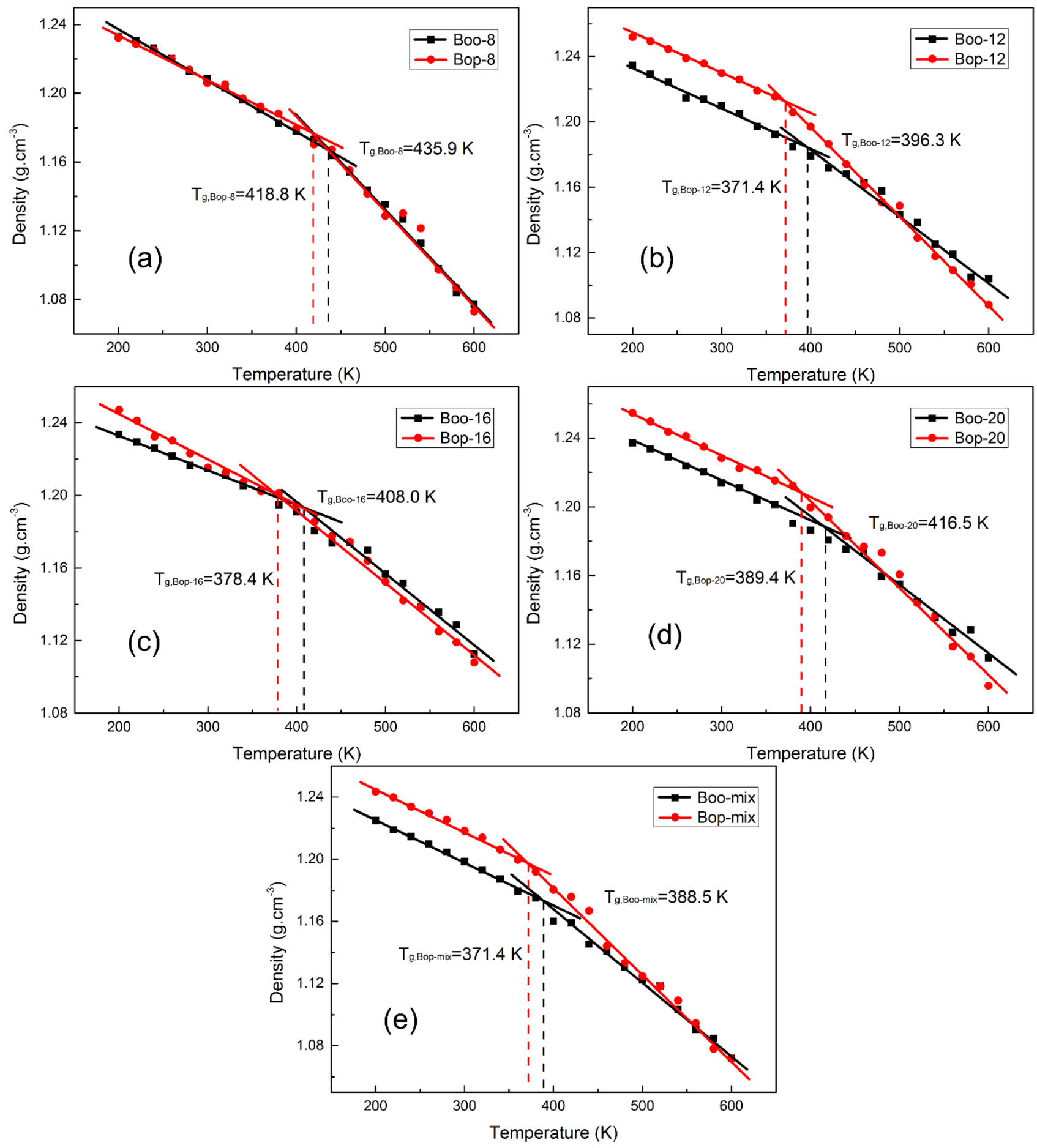

Figure S6 Glass transition temperatures based on density temperature relationship of Boo-8 and Bop-8

(a), Boo-12 and Bop-12 (b), Boo-16 and Boo-16 (c), Boo-20 and Boo-20 (d), Boo-mix and Bop-mix (e).

The density temperature data were obtained from a gradually cooling down process with a cooling rate of $20 \mathrm{~K} / 200$ ps. Densities of the last 500 frames in 1000 frames at each temperature were averaged. 

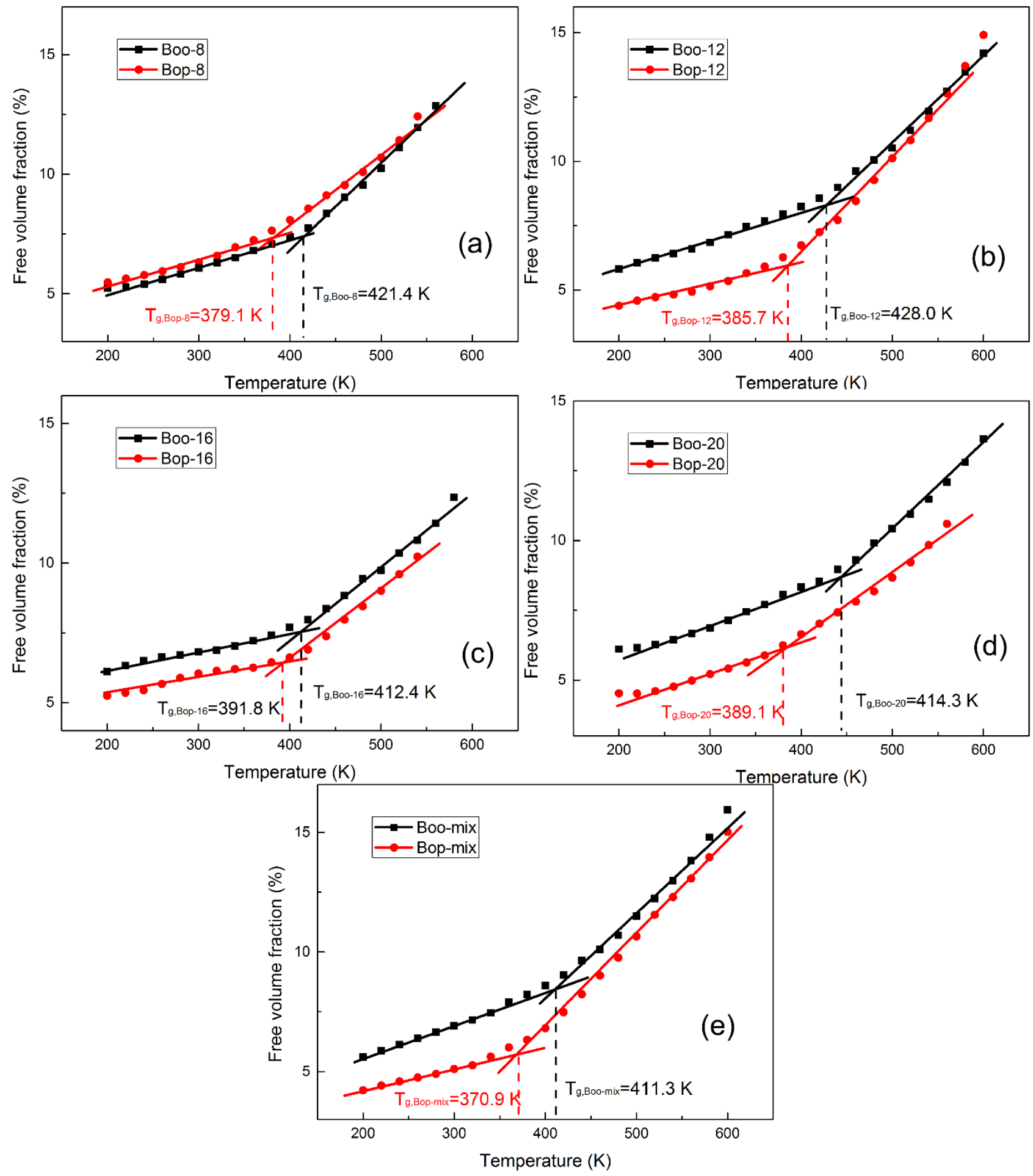

Figure S7 The free volume fraction temperature relationship of Boo-8 and Bop-8 (a), Boo-12 and Bop-12 (b), Boo-16 and Boo-16 (c), Boo-20 and Boo-20 (d), Boo-mix and Bop-mix (e). The free volume for each model were calculated with a probe radius of $1.4 \AA$. 

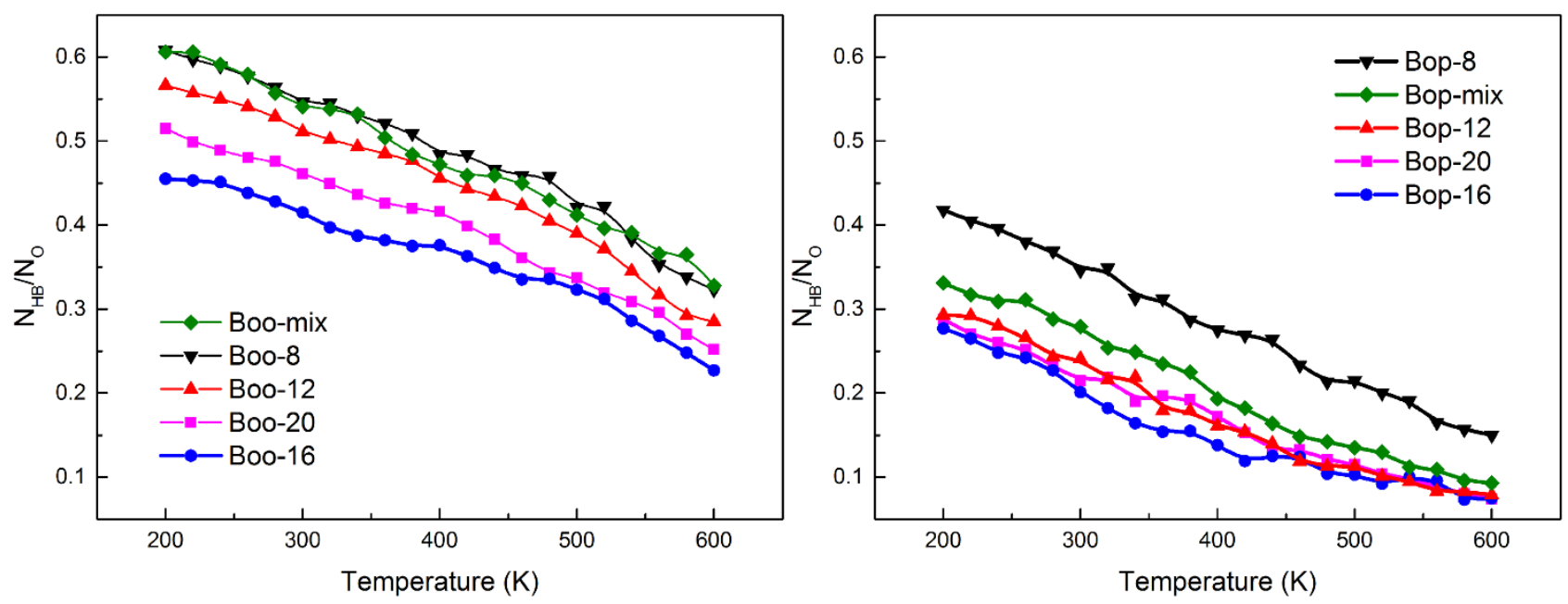

Figure S8 The ratio of hydrogen bonds number to total oxygen number for Boo-x (left) and Bop-x (right).

There are obvious infection points (about $400 \mathrm{~K}$ ) in $\mathrm{N}_{\mathrm{HB}} / \mathrm{N}_{\mathrm{O}} \sim$ temperature curve of Boo-x, while the infection points of Bop-x curves are not significant.
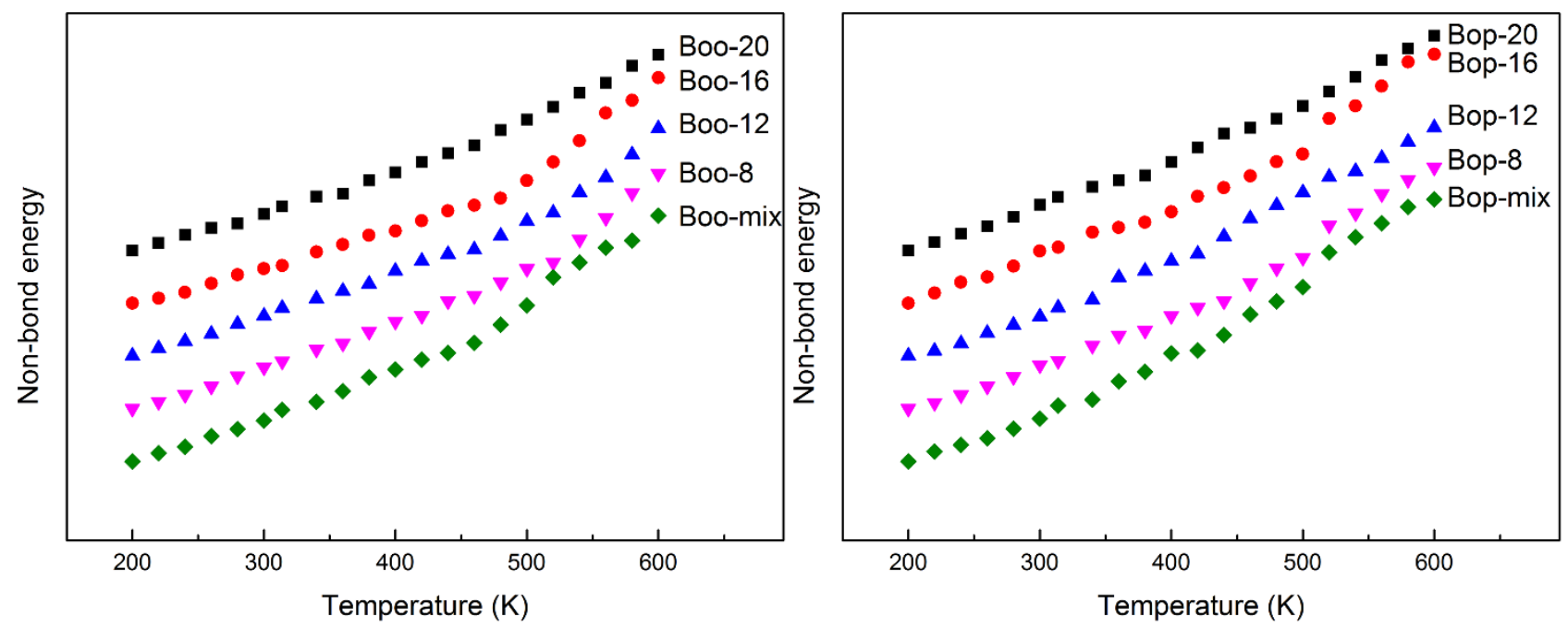

Figure S9 Nonbond energy (including van der Waals, hydrogen bond and electrostatic energy) change during the cooling down process of Boo-x (left) and Bop-x (right). There are obvious inflection points around $500 \mathrm{~K}$ for $\mathrm{DP}=8 \sim 12$ and Boo-mix/Bop-mix. 

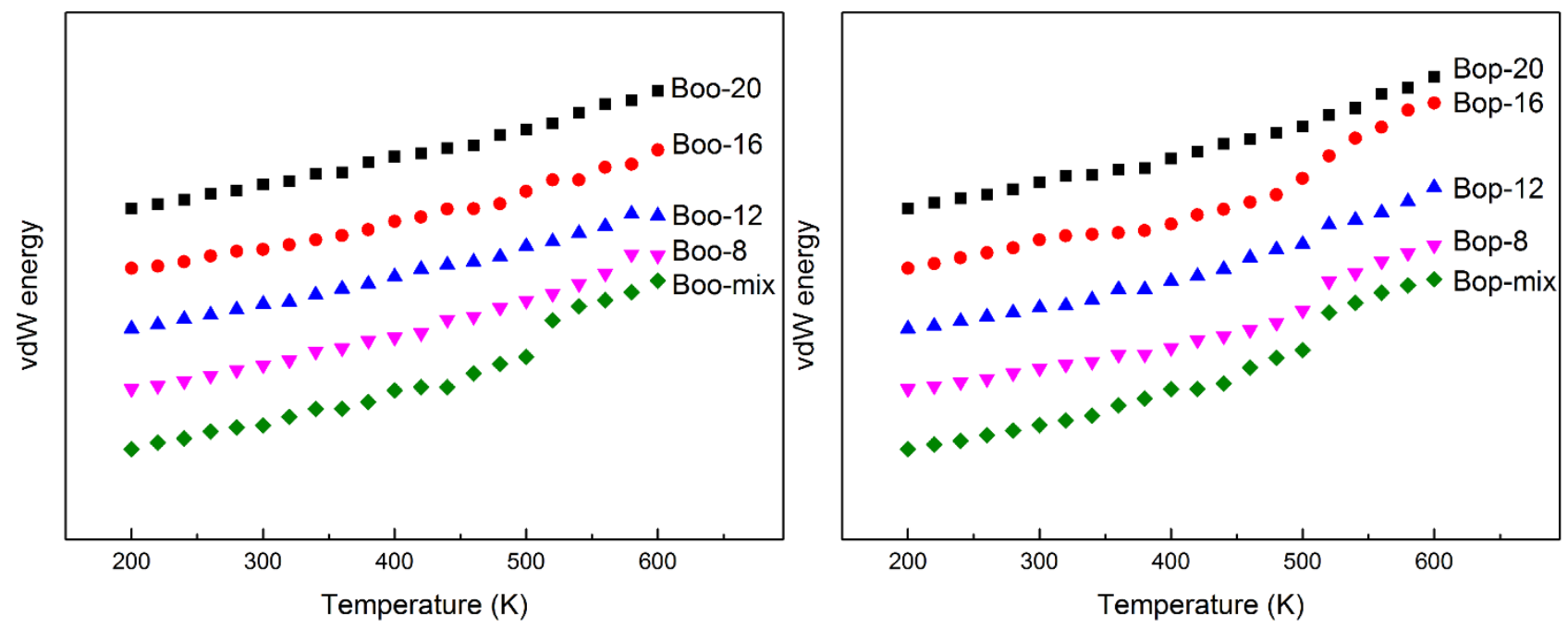

Figure S10 Van der Waals energy change during the cooling down process of Boo-x (left) and Bop-x (right). There are obvious inflection points around $500 \mathrm{~K}$ for Boo-mix, Bop-mix, Bop-8 and Bop-16.
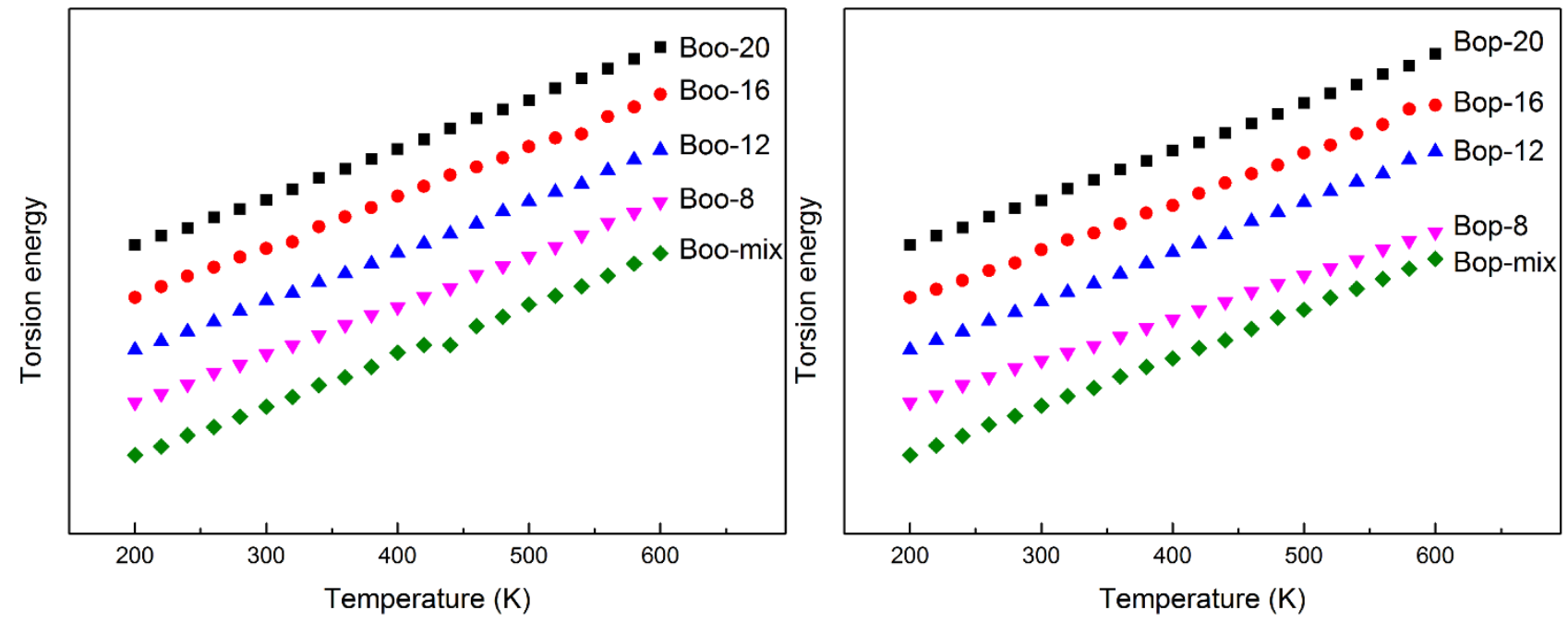

Figure S11 Torsion energy change during the cooling down process of Boo-x (left) and Bop-x (right).

There is no obvious inflection in the torsion energy temperature curves. 


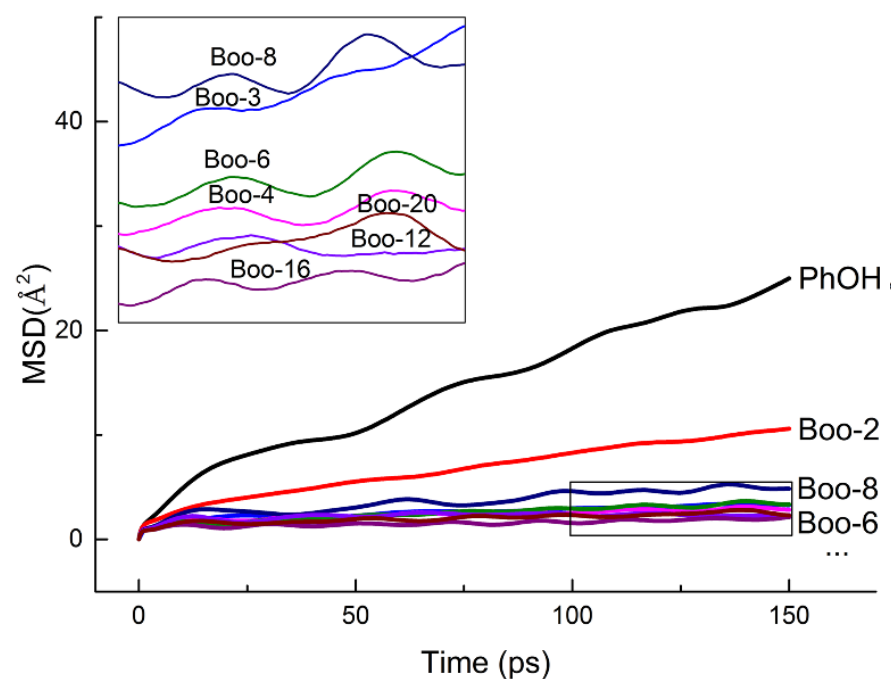

(a)

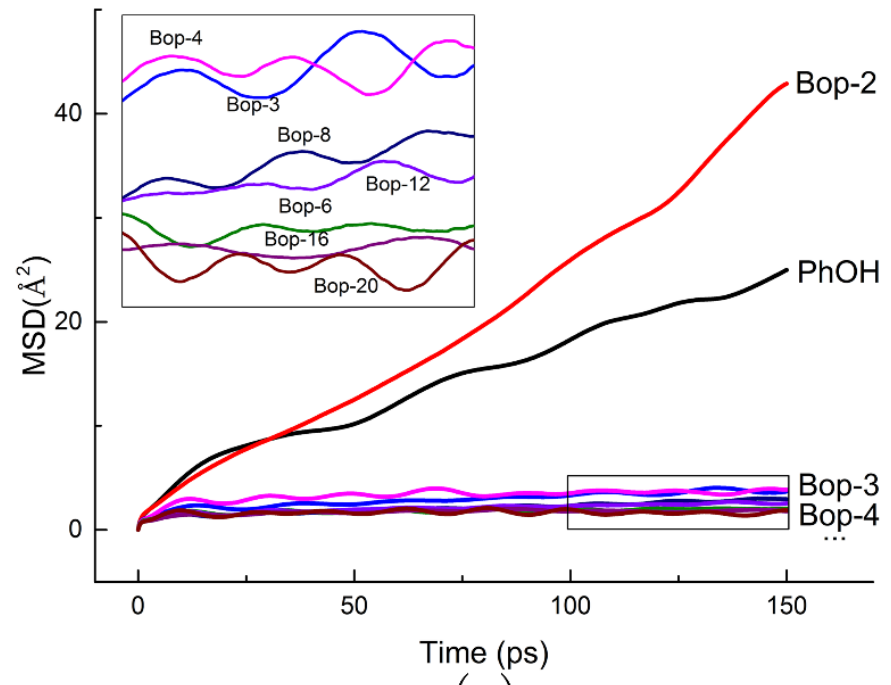

(c)

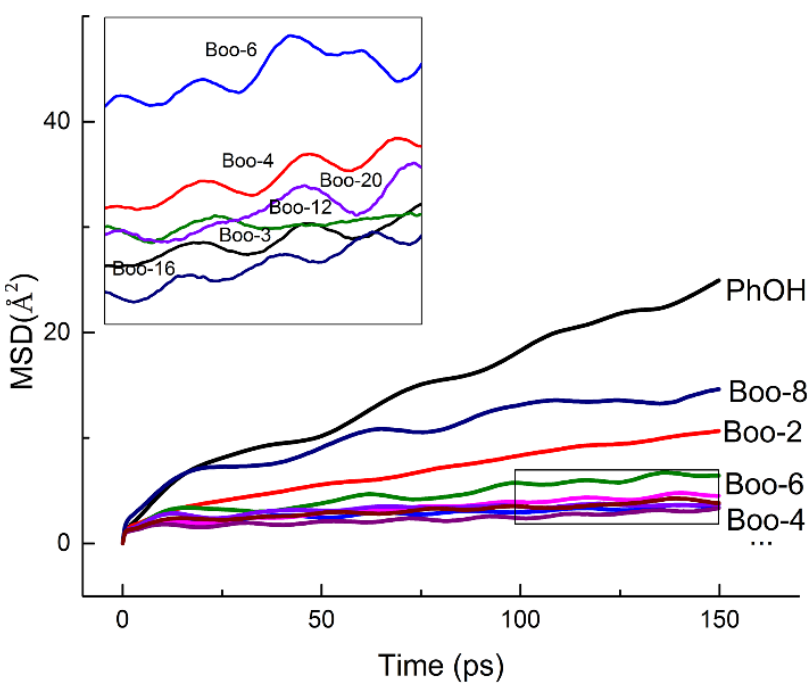

(b)

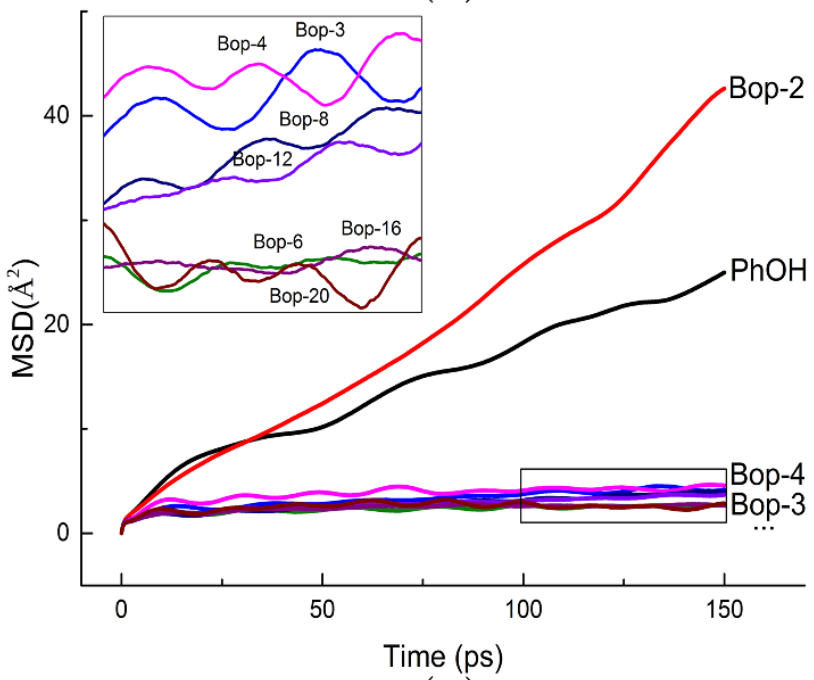

(d)

Figure S12 MSD of atoms in novolac models at $300 \mathrm{~K}$ : (a) all atoms in Boo-x; (b) end phenol rings in Boo-x; (c) all atoms in Bop-x; (d) end phenol rings in Bop-x. There are obvious differences among phenol, Boo-2/Bop-2 and other novolacs. In order to observe these curves in one figure, the data at the range of $0-150$ ps were adopted. 

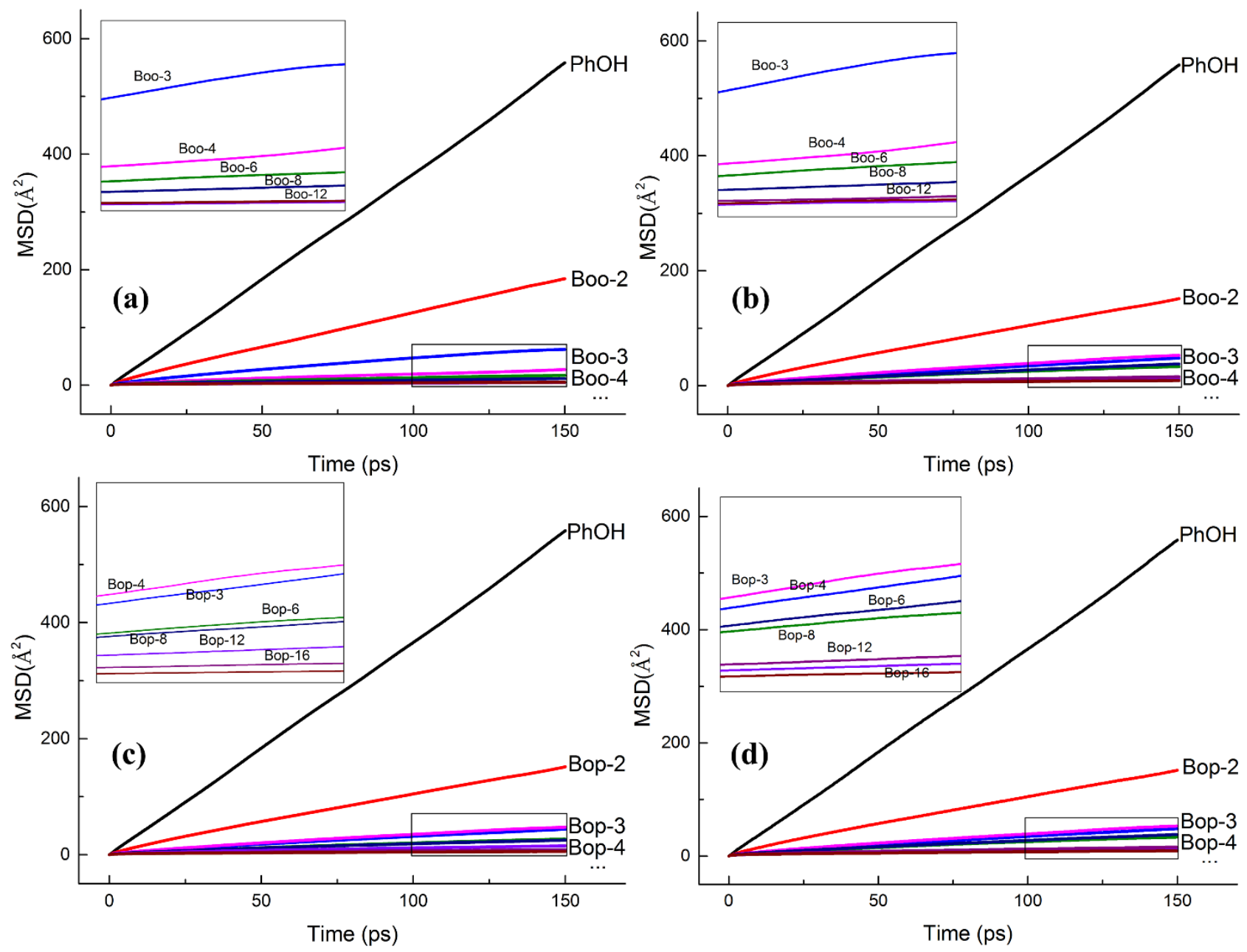

Figure S13 MSD of atoms in novolac models at $540 \mathrm{~K}$ : (a) all atoms in Boo-x; (b) end phenol rings in Boo-x; (c) all atoms in Bop-x; (d) end phenol rings in Bop-x. 


\section{IV . Nearest coordination numbers of oxygen atoms}

The nearest coordination number $(Z)$ is calculated with the most commonly used definition:

$$
Z=4 \pi \rho_{0} \int_{r_{\min }}^{r_{\max }} g(r) r^{2} d r
$$

Where $\mathrm{g}(\mathrm{r})$ is the RDF of oxygens, $r_{\min }=2.3 \mathrm{~A}$ and $r_{\max }=3.4 \mathrm{~A}$ were adopted in this study; $\rho_{0}$ is the number density of oxygen atoms in each models.
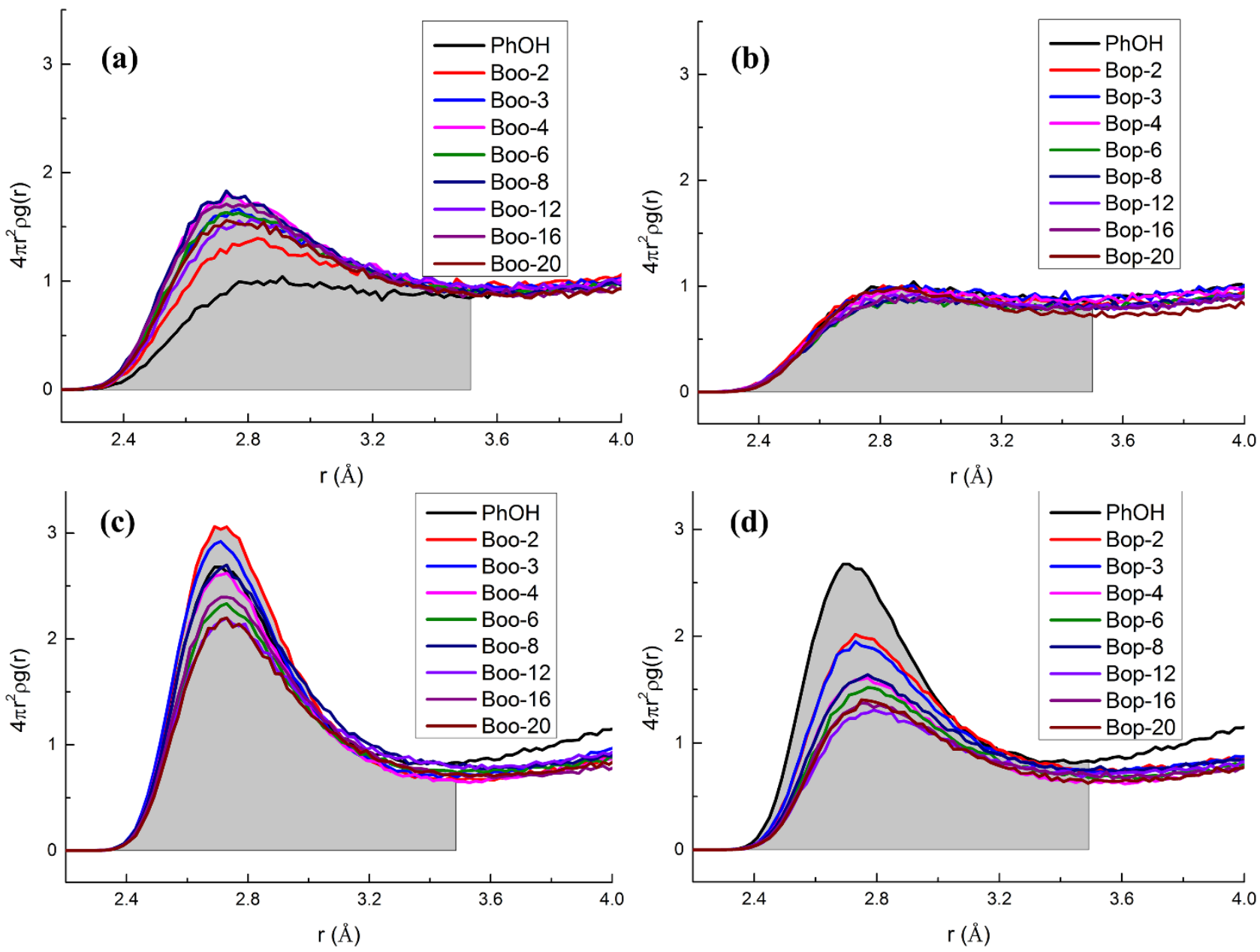

Figure S14 4 $\mathrm{r}^{2} \rho g(r)$ curve of O...O in: (a) Boo-x at $300 \mathrm{~K}$; (b) Boo-x at $540 \mathrm{~K}$; (c) Bop-x at $300 \mathrm{~K}$; (d) Boo-x at $540 \mathrm{~K}$ 


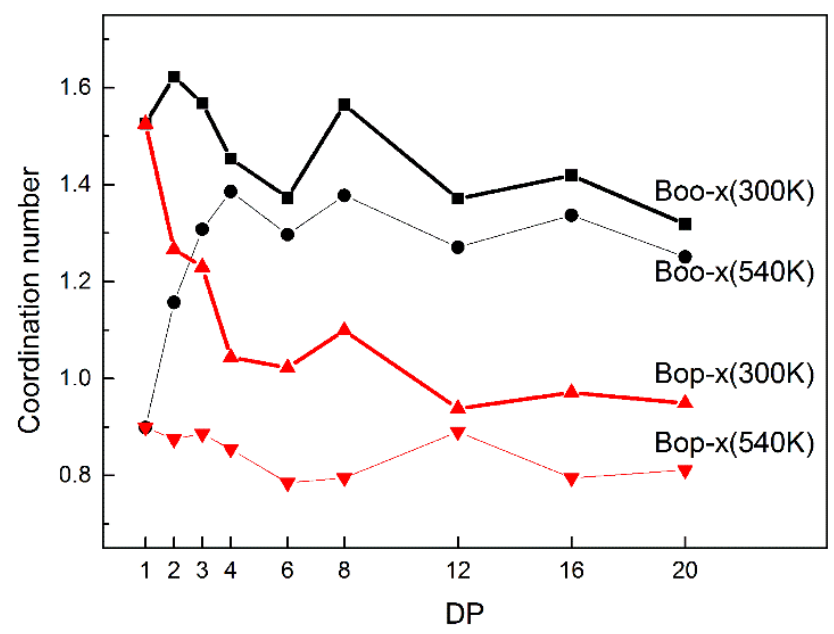

Figure S15 Nearest coordination numbers of oxygen atoms in Boo-x and Bop-x

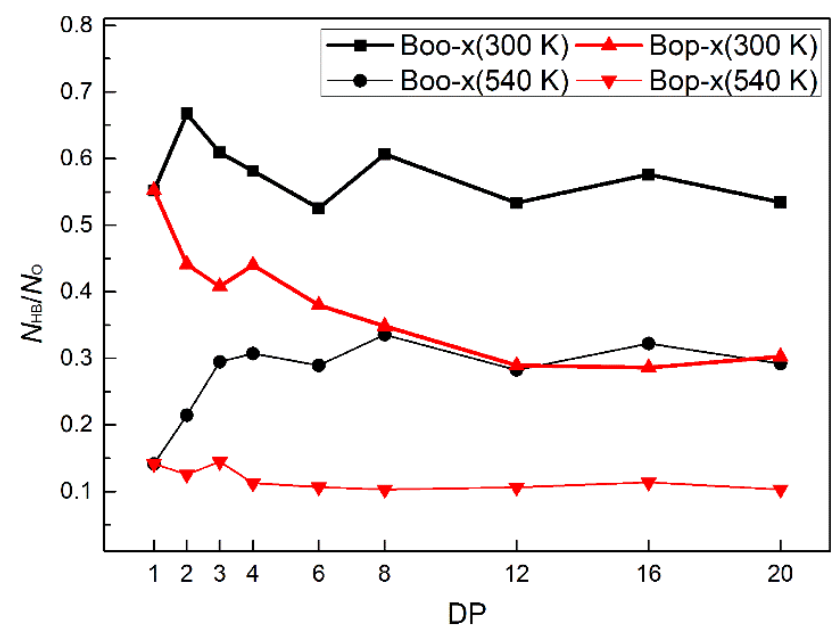

Figure S16 Ratio of hydrogen bonds to total oxygen atoms $\left(\mathrm{N}_{\mathrm{HB}} / \mathrm{N}_{\mathrm{O}}\right)$ in novolac models

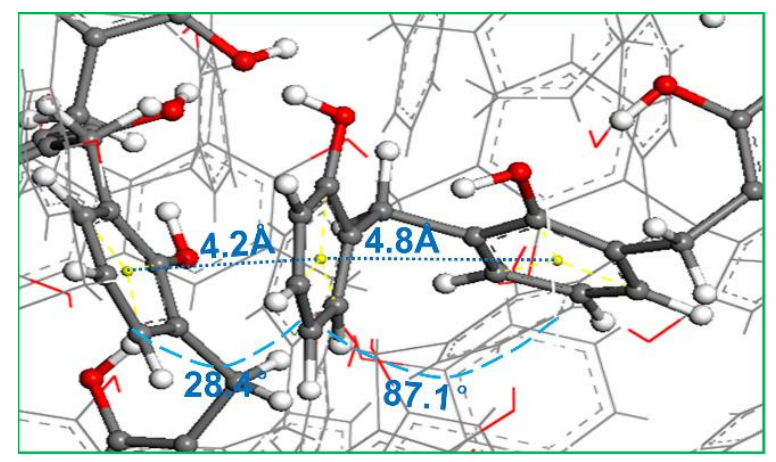

Figure S17 Distances and angles between phenolic ring pairs in Boo-8. The typical distance between the methylene linked phenolic ring pair is $4.8 \AA$, while $4.2 \AA$ for phenolic ring pair that are not bridged. 


\section{V . Averaged reduced density gradient of frozen end phenolic rings}

The following color codes are employed to distinguish interaction types of noncovalent interaction:

- Blue for the highly attractive interactions (such as hydrogen bonds)

- Green for the weak interactions (such as dispersive-like van der Waals)

- Red for repulsive interactions (such as steric clashes)
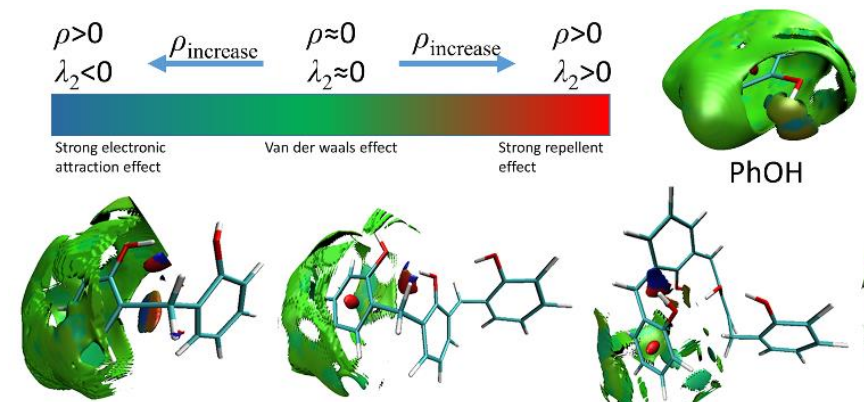

Boo-2

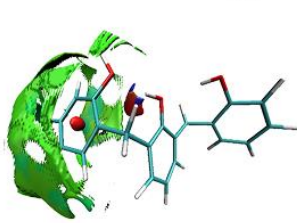

Boo-3

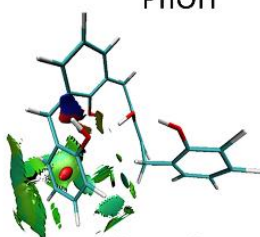

Boo-4

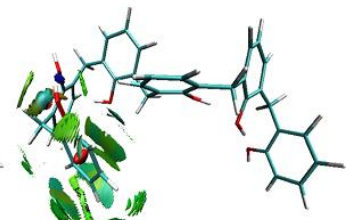

Boo-6

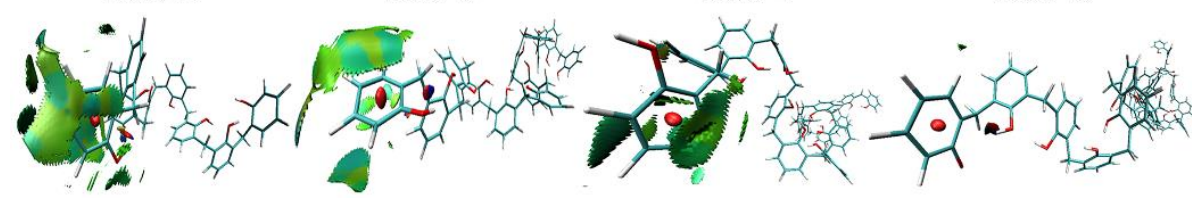

Boo-8

Boo-12

Boo-16

Boo-20

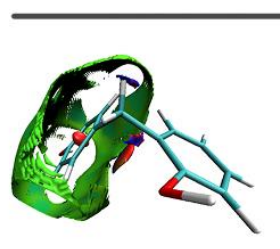

Bop-2

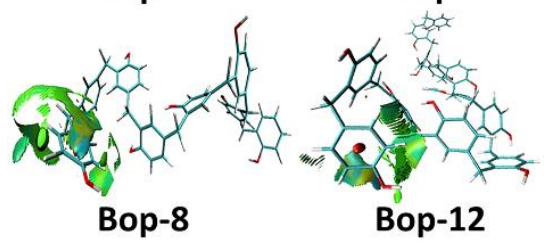

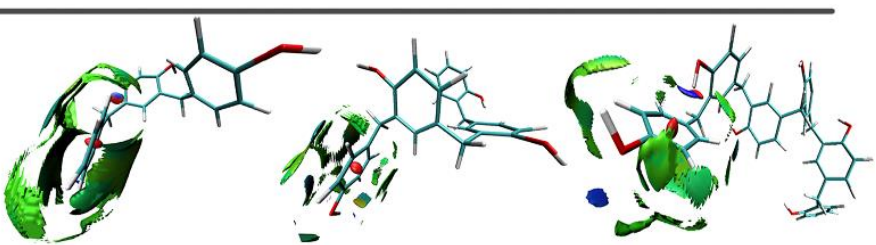

Bop-6

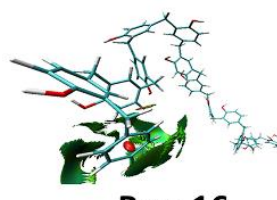

Bop-16

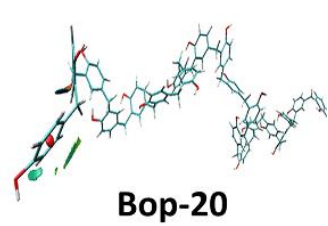

Bop-20

Figure S18 Reduced density gradient isosurfaces $\left(\mathrm{s}^{\mathrm{pro}}=0.35\right)$ for interaction of frozen end phenol ring in Boo-x and Bop-x at $540 \mathrm{~K}$. The surfaces are colored on a blue-green-red scale according to values of $\operatorname{sign}\left(\lambda_{2}\right) \rho$, ranging from -0.06 to +0.05 au. Blue indicates strong attractive interactions, and red indicates strong nonbonded overlap. 

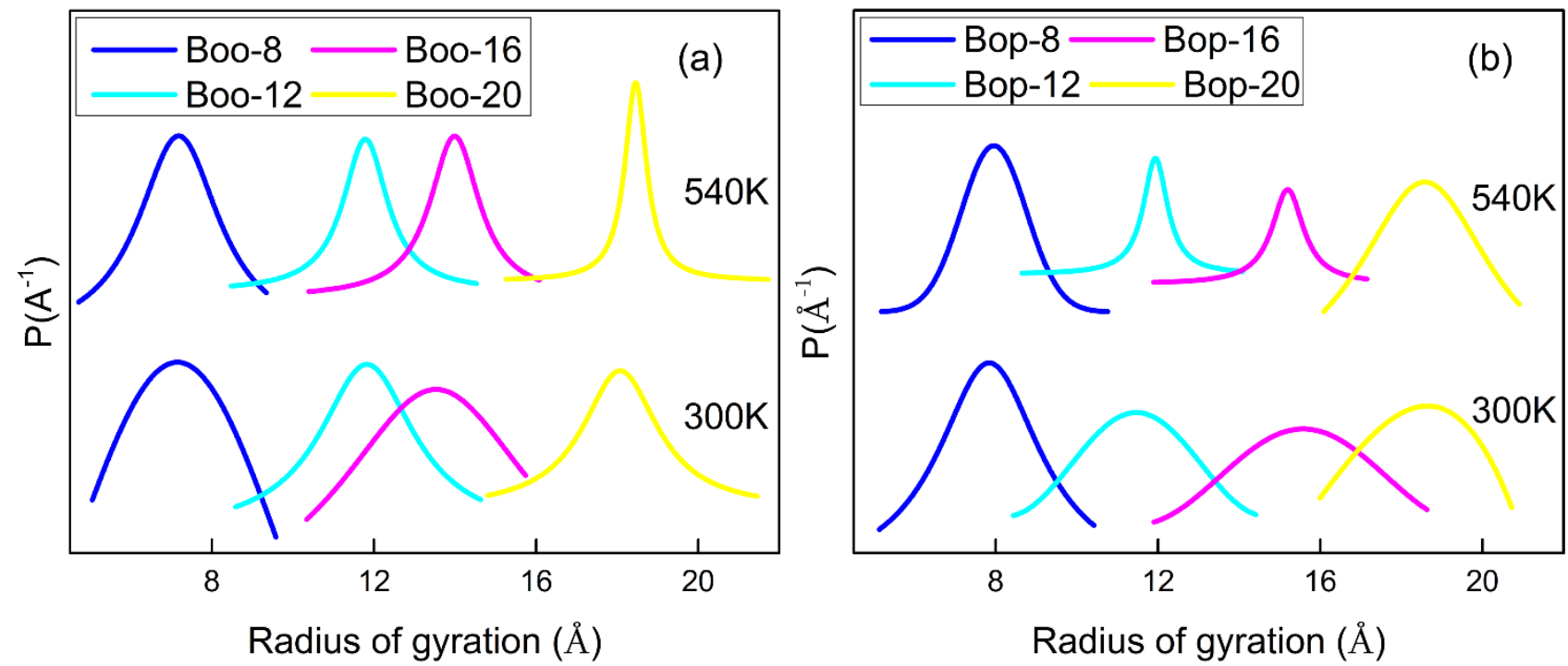

Figure S19 Probability distribution of the radius of gyration $\left(R_{\mathrm{g}}\right)$ of Boo-x (a) and Bop-x (b). The novolac chains, both in Boo-x and Bop-x, tend to stretch out at $540 \mathrm{~K}$, lead to narrow distributed $R_{\mathrm{g}}$ distribution curves.

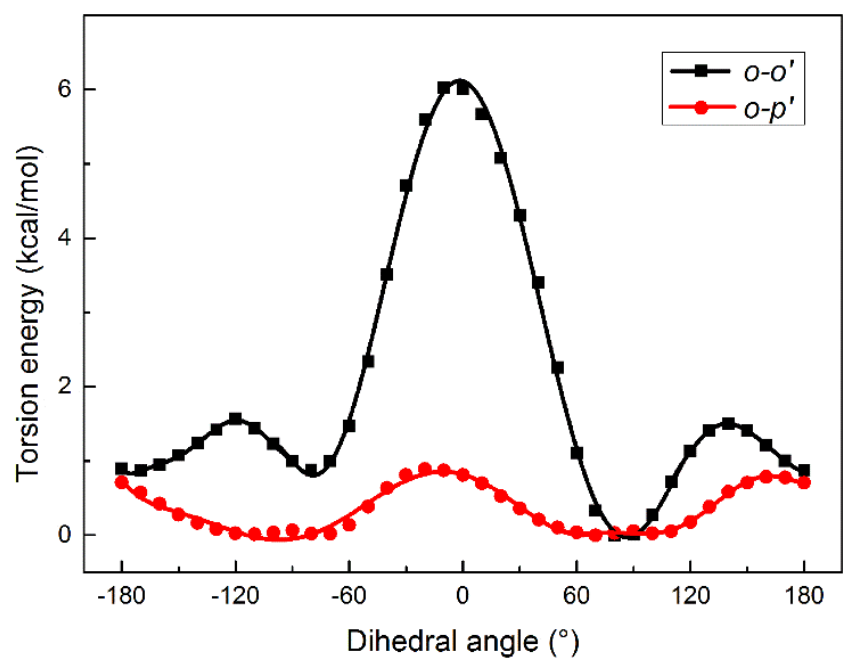

Figure S20 The minimum energy path of the torsion energy v.s. dihedral angles in Boo-2 (black dots) and Bop-2 (red dots). 
Table S5 Boltzmann average of $\cos \varphi$ for Boo-2 and Bop-2

\begin{tabular}{lll}
\hline & $300 \mathrm{~K}$ & $540 \mathrm{~K}$ \\
\hline Boo-2 & 0.028 & 0.065 \\
Bop-2 & 0.120 & 0.122 \\
\hline
\end{tabular}

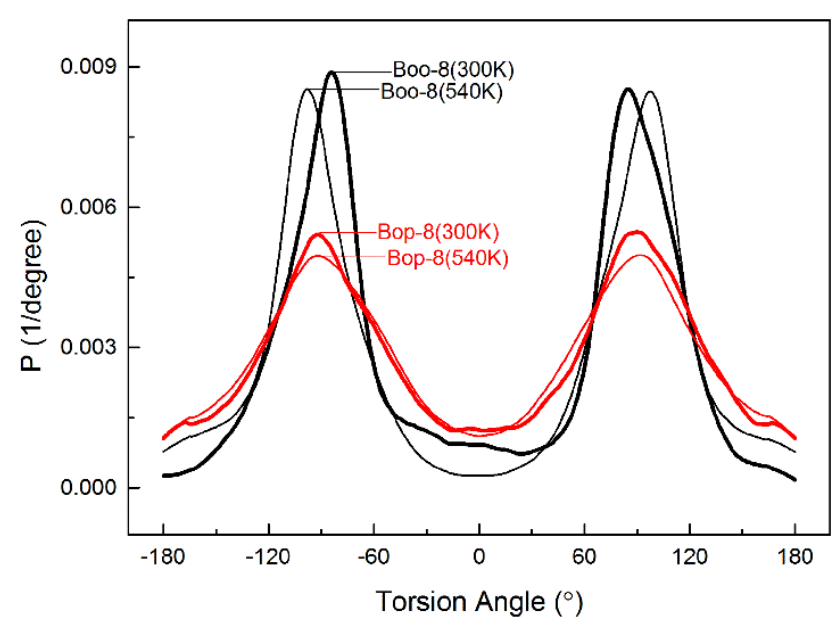

Figure S21 Dihedral angel distribution in Boo-8 (black lines) and Bop-8 (red lines) 